\title{
Daily client utilization of Stand Alone Integrated Counseling and Testing Centers in North Eastern States of India.
}

\author{
Arpana Barman ${ }^{1}$, Dr. Pranab R. Nath ${ }^{2}$ \\ ${ }^{1}$ (NE Regional Office, Department of AIDS Control, India) \\ ${ }^{2}$ (NE Regional Office, Department of AIDS Control, India)
}

\begin{abstract}
Integrated HIV Counselling and Testing (ICT) is one of the prevention programs under National AIDS Control Program for reducing HIV epidemic in India. The key method of knowing ones HIV status is through Integrated Counselling and Testing Centres (ICTCS). It is important to maximize the reach of ICTCs by providing counselling services to reach maximum number of people. The study analyses per day counselling in Stand Alone ICTCs of North East Region of India to discuss the implications and look for ways of improving the efficiency of the system. Consolidated counselling data of NE states from 2007-08 to 2012-13 is reviewed and analysed. Trend analysis is done to study the coverage of various typology of clients. Results of the analysis shows that, per day counselling in ICTCs has increased from 1-7. For improving the functioning of ICTCs focus should be on the nature of epidemic, cost effectiveness, equity of access and resources available at various level with respect to difficult geographical terrain of the region.
\end{abstract}

Keywords: Client, Counselling, Integrated, Stand-Alone

\section{Introduction}

North East India consists of eight states (Arunachal Pradesh, Assam, Manipur, Meghalaya, Mizoram, Nagaland, Sikkim and Tripura) and has a population of 454 lakhs (Census 2011). Over all HIV epidemic in North East India is showing an increase in adult new infections [1]. In order to achieve the National AIDS Control Program Phase IV (NACP-IV) objective of reducing new infections by $50 \%$ and providing comprehensive care, support and treatment to all persons living with HIV/AIDS between 2012-17 [2], it is of utmost importance in monitoring the prevention programs.

Integrated HIV Counselling and Testing (ICT) is one of the prevention programs for reducing the HIV epidemic in India. As HIV infection does not provide any specific clinical features in early infection the key method of knowing ones HIV status is based on counselling undertaken in Integrated Counselling and Testing Centres (ICTCs). A significant proportion of people living with HIV, including people living in high-income countries[3], remain undiagnosed until they become symptomatic, therefore linked late for treatment [4], [5]. The HIV test offered in these centres not only facilitate identification of those who are positive but also provide the opportunity to those who are at risk or perceive to be at risk etc. to understand the risks and prevention methods which will lead to HIV free life. The contribution of ICTC for HIV prevention is beyond HIV counselling, as it adds value in early detection of TB, ensuring positive pregnant women receive Multi Drug Regimen, children born to positive mothers receive care, support and treatment. It also provides psycho-social support to affected and infected individuals.

As ICTC is considered as entry point to HIV services it is important to maximize the reach of the same by providing counselling and testing services to reach to maximum number of people. The overall goal for ICTCs should be to identify as many people as possible with HIV early in their infection and link them successfully to prevention, care and treatment services, and to link those who test negative to prevention services[6]. Expansion of counseling and testing services to community have reduced stigma and discrimination associated with HIV [7].

During NACP I and NACP II, awareness about HIV counselling and testing centres in Govt. health facility is generated. This awareness has created the demand generation of ICTCs and over the period of NACP III, the utilization of ICTCs has improved. 
Table 1: Awareness about HIV Counselling and Testing services in NE states.

\begin{tabular}{|c|c|c|c|c|c|c|c|c|}
\hline \multirow[t]{2}{*}{ State } & \multirow{2}{*}{$\begin{array}{l}\text { Know } \\
\text { place } \\
\text { where to } \\
\text { get tested }\end{array}$} & \multicolumn{4}{|c|}{ Govt. health facility } & \multicolumn{3}{|c|}{ Pvt. health facility } \\
\hline & & Hospital & $\begin{array}{l}\mathrm{CHC} / \mathrm{PHC} \\
\text { /SC }\end{array}$ & $\begin{array}{l}\text { RTI/ } \\
\text { STI Clinic } \\
\text { VCT/ICTC }\end{array}$ & $\begin{array}{l}\text { Other } \\
\text { public/ } \\
\text { NGO } \\
\text { Hospitals }\end{array}$ & Hospital & $\begin{array}{l}\text { RTI/STI } \\
\text { Clinic } \\
\text { VCT/ICTC }\end{array}$ & $\begin{array}{l}\text { Other } \\
\text { private } \\
\text { hospitals }\end{array}$ \\
\hline Arunachal* & 77.0 & 94.7 & 12.6 & 3.7 & 3.7 & 19.9 & 2.5 & 4.6 \\
\hline Assam** & 43 & 94.7 & 8.8 & 2.7 & 2.5 & 14.0 & 2.8 & 1.6 \\
\hline Manipur* & 54.6 & 72.7 & 10.2 & 1.0 & 2.5 & 11.8 & 0.9 & 0.9 \\
\hline Meghalaya* & 41.5 & 54.8 & 13.5 & 1.8 & 2.1 & 24.5 & 1.3 & 1.9 \\
\hline Mizoram** & 66.2 & 91.1 & 7.4 & 20.2 & 1.6 & 12.4 & 3.7 & 1.9 \\
\hline Nagaland & \multicolumn{8}{|c|}{ Data not available } \\
\hline Sikkim** & 55.8 & 97.0 & 2.2 & 3.3 & 1.3 & 12.0 & 0.8 & 0.5 \\
\hline Tripura* & 34.3 & 59.7 & 11.2 & 0.2 & 4.7 & 18.0 & 1.2 & 5.0 \\
\hline
\end{tabular}

Source: DLHS-3

$* \%$ of ever married women aged $15-49$ years.

$* * \%$ of unmarried women aged $15-24$ years.

Stand alone ICTCs are the core stone of institutionalised prevention program where counsellor and laboratory technicians are provided under the National AIDS Control Program. Over the period of time the program has established mechanisms and institutionalised the system of rigorous trainings, supportive supervision, quality control systems for counselling and testing. These mechanisms focused towards delivering quality services to those who come to ICTC.

NACP-IV targets for 17.5 million clients to be counselled and tested in Integrated Counselling and Testing Centres (ICTCs) across India [2]. In this analysis effort has been made to look in the client uptake of the existing standalone ICTC in a geographically difficult region, discuss the implications on the current understanding of the epidemic and look for ways and means of improving the efficiency of the system with the perspective reasonable HIV response at the local level.

\section{Objectives of the Study}

- To analyse utilization of Stand Alone Integrated Counselling and Testing Centers

- To highlight the implications to HIV response of the geographical difficult region.

\section{Methodology}

ICTC data provides information on the General Client and Antenatal clinic (ANC) attendees. Stock out of HIV testing kits in the facility is not taken into consideration for this study. It is assumed that, HIV test kits are present in the facility. For understanding number of Counselling per day, counselling numbers of general client, ANC, client initiated and provider initiated including number of reporting SA-ICTCs is taken from 200713. Taking 25 working days in a month, per day client uptake is calculated against each ICTC of the state. As the number of counselling is not same across the years thus moving average is calculated for analyzing the trend of per day client uptake.

\section{Availability of SA-ICTCs}

\section{Analysis And Results}

There are more than 300 SA-ICTCs in NE states. 56 centres are exclusive PPTCT centres catering to Antenatal cases/Pregnant Women and 31 Mobile ICTCs providing community-based counselling. There is $85 \%$ increase of ICTCs over a period of 5 years. Details given in below table:

\begin{tabular}{|l|c|c|c|c|c|c|}
\hline States & $\mathbf{2 0 0 7 - 0 8}$ & $\mathbf{2 0 0 8 - 0 9}$ & $\mathbf{2 0 0 9 - 1 0}$ & $\mathbf{2 0 1 0 - 1 1}$ & $\mathbf{2 0 1 1 - 1 2}$ & $\mathbf{2 0 1 2 - 1 3}$ \\
\hline Arunachal Pradesh & 34 & 34 & 34 & 35 & 35 & 35 \\
\hline Assam & 82 & 80 & 84 & 85 & 85 & 86 \\
\hline Manipur & 51 & 52 & 64 & 59 & 59 & 59 \\
\hline Meghalaya & 10 & 9 & 12 & 12 & 10 & 15 \\
\hline Mizoram & 32 & 32 & 46 & 36 & 35 & 37 \\
\hline Nagaland & 62 & 62 & 67 & 71 & 71 & 71 \\
\hline Sikkim & 13 & 13 & 13 & 13 & 13 & 13 \\
\hline Tripura & 9 & 9 & 17 & 18 & 18 & 18 \\
\hline
\end{tabular}

\section{Per day Counselling}

Per day Counselling is the basic indicator of understanding the performance of ICTC, Following trend analysis ( figure-1) of per day counselling in ICTCs (including general client and ANC) shows that during this 
period, the number of clients counselled per day at the stand alone ICTC have increased from 1 to 7 . During the same period Assam, Tripura, Meghalaya \& Sikkim is showing gradual increasing trend, while state of Arunachal is showing stable trend of per day 3 clients since 2010-11. These results need to reflect with the fact that these five states have reported increasing trend of adult new positives [1]. The state of Nagaland is showing a stable trend of 4 per day since 2010-11 while Manipur and Mizoram are showing a stable trend of 5 per day and 6 per day since 2011-12.

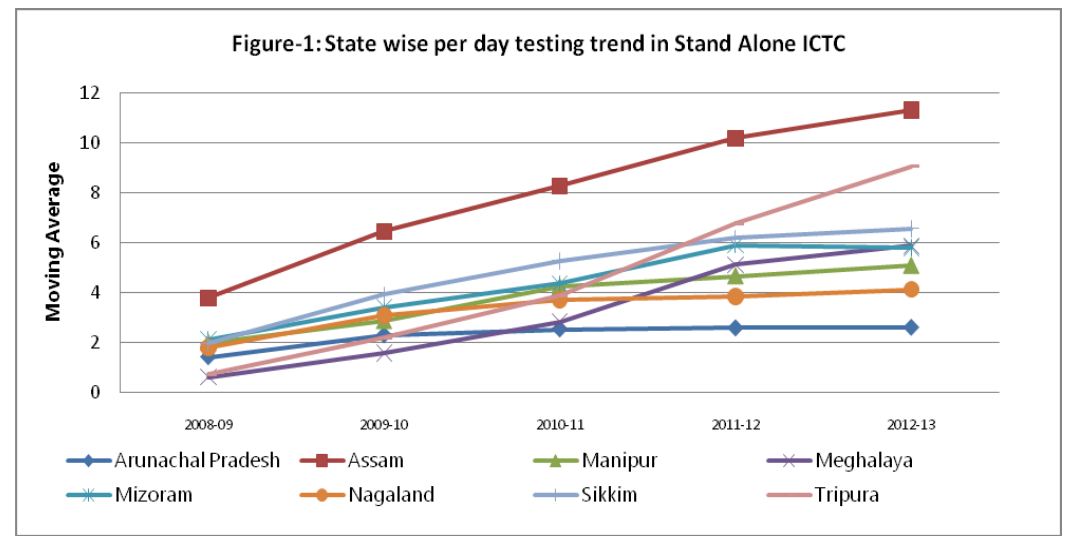

\section{General Client}

General clients include all male and MSM(Men having Sex with Men)/TG(Transgender) and female who are not pregnant at the time of counselling. During this period, the number of counselling undertaken for general clients per day at the stand alone ICTC have increased from 1 to 4 . Details of trend analysis (Figure-2) of general clients are given below.

- Stable trend of 2 clients per day is observed in Arunachal Pradesh for last 4 years. Similar trend of 3 per day is observed in Nagaland for last 3 years.

- Increasing trend of general client counselling per day is observed in Meghalaya, Sikkim, Tripura. Increasing trend is observed after every 2 years in Assam, Manipur and Meghalaya.

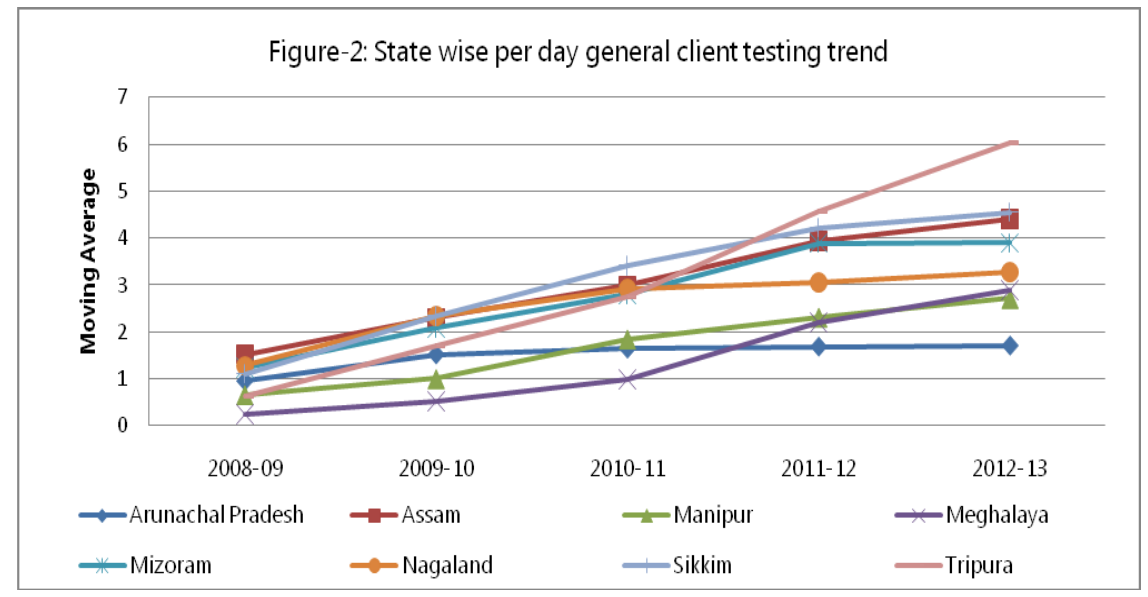

\section{Antenatal Cases/Pregnant Women}

During this period, the number of ANC clients or pregnant women counseled per day at the stand alone ICTC have increased from 1 to 4 . As a policy the program is working towards institutionalising HIV counselling as part of routine Antenatal Care. Increasing trend is observed in Assam, Meghalaya \& Tripura. For last 4 years, stable trend, of 1 client per day is observed in Arunachal Pradesh \& 2 per day is observed in Manipur \& Sikkim. Similar trend of 2 per day is observed in Mizoram for last 3 years. Considering these are fully staffed ICTC supported by program and the importance of the ICTC in preventing HIV is manifold, the poor number of counselling done in the above states. More importantly as NACP IV is focussing to roll out multidrug regimen for positive pregnant women, poor counselling in the states will lead to, many of those need services not getting what they need to get. 


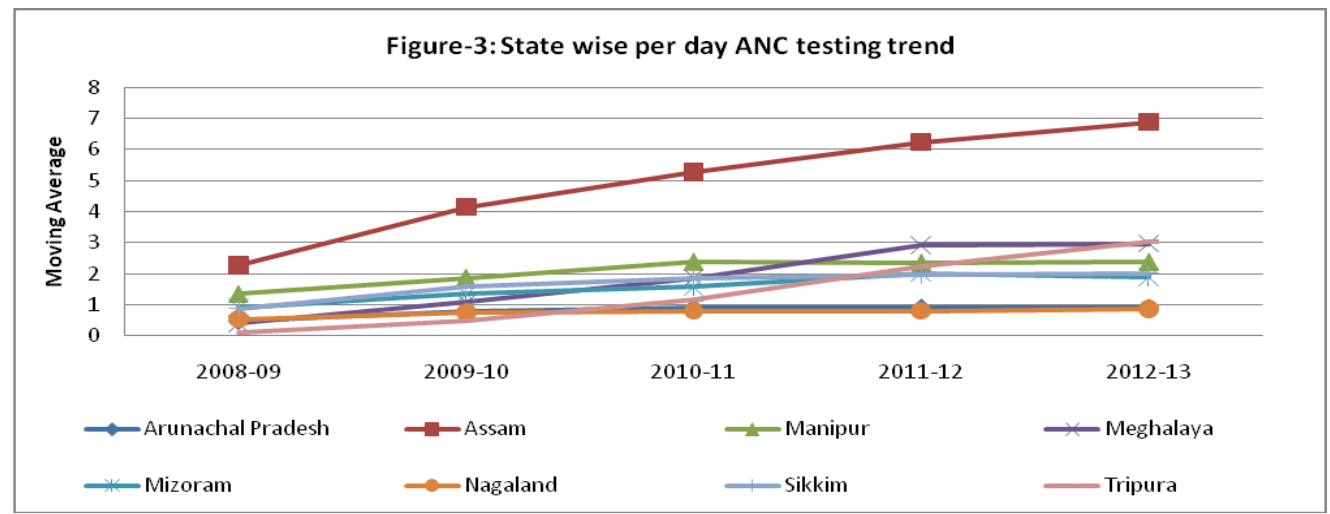

\section{Client Initiated Counselling}

Client Initiated Counselling indicates the direct walk-in clients to the facilities. Analysis of per day client initiated counselling shows that, Arunachal Pradesh is showing (figure-4) a stable trend of 1 counselling per day since 2007-08. Assam is showing a gradual improvement from 2 per day during 2008-09 to 3 per day in 2009-11 and then a declining trend to 2 per day till 2012-13. Manipur is showing a gradual improvement from 1 per day in 2008-10, to 2 per day stabilizing till 2012-13. Meghalaya is having client counselling from 2011-12 with 1 per day and is stabilizing till 2012-13. Mizoram, Nagaland, Sikkim and Tripura are showing gradual improvement from 1 per day to 3 per day. This reflects the contribution of community based targeted intervention programs and IEC program in creating demand generation of ICTCs in a constrained setting.

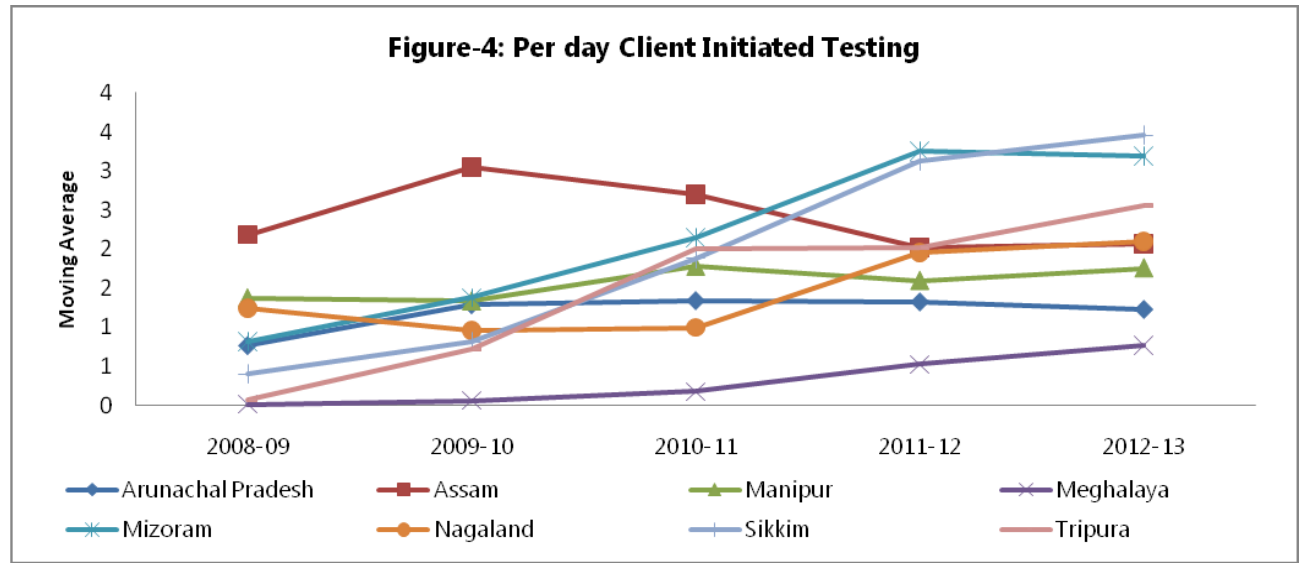

\section{Provider Initiated Counselling}

Provider Initiated Counselling is a key component of HIV counselling for those who might have missed the opportunity through the Client Initiated Counselling mechanism. As most of those who visit the medical set up visit the clinicians for certain health conditions, the scope of screening this population by offering counselling and testing is important in Indian health system. The same has been found productive in finding many positive cases most importantly finding undiagnosed cases among children who could be benefited from opportunistic infections ( by providing CPT) and Anti-Retroviral Therapy. Analysis of per day Provider Initiated Counselling in ICTCs ( Figure-5) shows that, Manipur, Meghalaya, Nagaland and Sikkim is having this referral from 2010-11. Arunachal is having Provider Initiated Counselling from 2012-13. Almost all the states are showing a stable trend of 1 per day. Assam is showing a stable trend of 1 counselling per day till 2009-10 with an increase and stable trend to 2 counselling per day from 2010-11. 


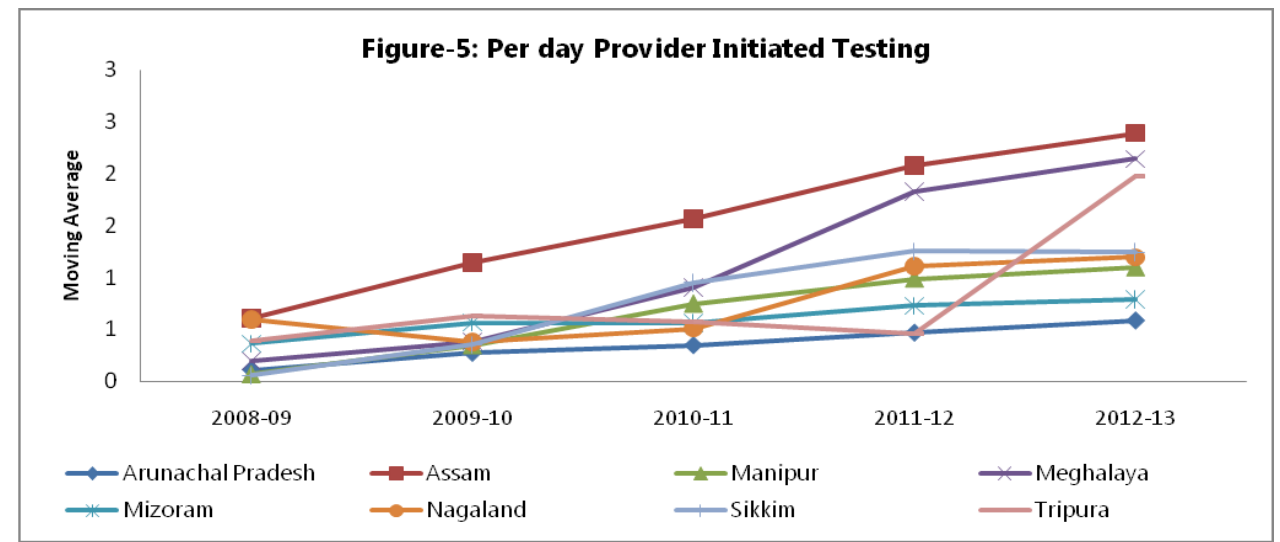

\section{Discussions}

The analytical framework used in this document is to revisit the HIV counselling strategies and most importantly taking reasonable results from the existing investments under the HIV response framework of the state. Though HIV counselling provides results, either positive or negative for the time being and provides information on safe behaviour is by no means is one time event for any population. The importance and continuity of the existing stand alone ICTC needs to be strengthened with the actual coverage of pregnant women and cohort of people who have never been counselled (including cohort of young people entering in to the adolescent/ adult age group) and those who are at risk. Client initiated counselling is considered as coverage of those who are self perceived risk, an increase in number of counselling in this sub group is expected to be in line with the increasing number of new adult infection which varies from state to state and remains an area of concern.

Counselling of pregnant women is critical first step for the long term multidrug regimen, however the ANC counselling in any given year is lower than the ANC check up numbers and there is a considerable variation from state to state. As long term regimen is more potent towards preventing HIV transmission from Mother to child, it is important that states also focus on increasing the per day counselling in the fully supported ICTC/PPTCT to ensure $100 \%$ ANC are counselled at institutions keeping in view of confidentiality.

Provider Initiated counselling and testing has become an integral part of ICTC. Keeping the low number of Provider Initiated Counselling in some of the states, it is important to strengthen referral, linkage and counselling from Revised National TB Control Program (RNTCP), Sexually Transmitted Infections (STI) Clinics, Oral Substitution Treatment (OST), private providers and blood bank. As the opportunity for Provider Initiated Counselling may vary from place to place local level decision and implementation of the same keeping the NACP IV objective in view is critical for increasing evidence based program coverage in the above states.

Setting counselling targets for ICTC may consider the details understanding and identification of the catchment area as much as possible, during the planning, implementation and monitoring of the ICTC. The importance of this can be reflected from the policy guideline which provides opportunity for the counsellors to make community out-reach once a week. Unless the geography is identified from the planning stage the implementation of the same will be difficult and thus leading to poor result in such a geographically difficult terrain. The client uptake in ICTCs may not be fully realised without consistent and high level support from other prevention programs like IEC and Targeted Interventions. The shared responsibility of functioning of ICTC with in concerned program divisions is important for reaching out to maximum population and providing them the much needed counselling and testing services, which will influence the epidemic in the region and the states.

As per the Operational Guideline of ICTCs-2007, performance of ICTCs in NE region is upto the programmatic requirement. But taking into account of the increasing trend of adult new infection more focus is to be given in this region. Considering the constraints in accessing the ICTCs of vulnerable region, following criteria needs to be taken into consideration for further improvement in client utilization.

1. Nature of Epidemic: Increasing new adult infections in five of the eight states, spread of epidemic from core group to general population, increasing number of sero discordant couples are few to mention here.

2. Cost effectiveness: Combination of efforts, as discussed above, to increase the per day counselling will add value to the effectiveness of ICTCs, combining the counselling services with the existing services like mobile vans, health camps and other outreach services would be of benefit. 
3. Equity of Access: Strategising the counsellor's weekly outreach to uncovered areas and mobilising the un reached population through IEC or Red Ribbon Club etc. would help address the issue of access and reach to un reached areas

4. Resources Available: Resources available needs to take in to consideration the recent developments in $\mathrm{RMNCH}+\mathrm{A}$, Mobile medical units, Boat Clinics, Private providers, FICTC , labour room counselling, and Blood Bank. Many of the above work as only screening centres where a proper linkage and timely result can maximise the services of Stand Alone ICTC.

\section{RECOMMENDATIONS:}

Considering the geography of the region, state specific strategies need to be developed. Factors limiting the accessibility of ICTCs need to be identified and addressed at local level. Effect of target based testing and facility integrated ICTCs on client utilization need to be done. More support in terms of technical is required to state for developing evidence based plan to address increasing adult new infections.

\section{Acknowledgement}

All State AIDS Control Societies of North Eastern States under Department of AIDS Control are acknowledged for their valuable support.

\section{References}

[1] Technical report, HIV Estimations India, 2011

[2] National AIDS Control Program - Phase IV (2012-2017): implementation plan, Department of AIDS Control, Ministry of Health and Family Welfare, Government of India; 2012.

[3] Coenen T et al. (2008). Optimal HIV testing and earlier care: the way forward in Europe. HIV Medicine, 9:1-5.

[4] Fairall T et al. (2008). Effectiveness of antiretroviral treatment in a South African program. A cohort study. Archives of Internal Medicine, 168(1):86-93.

[5] Kigozi I et al. (2009). Late disease stage at presentation to an HIV clinic in the era of free antiretroviral therapy in sub-Saharan Africa. Journal of Acquired Immune Deficiency Syndromes. 52(2):280.

[6] Service delivery approaches to HIV counselling and testing (HTC): a strategic HTC programme framework, WHO, 2

[7] Khumalo-Sakutukwa G et al. (2008). Project Accept (HPTN 043): A community-based intervention to reduce HIV incidence in populations at risk for HIV in sub-Saharan Africa and Thailand. Journal of Acquired Immune Deficiency Syndromes, 49(4):422431. 